\title{
GESTIÓN DE DIRECCIONES Y VIARIOS: DIFICULTADES PARA LA GENERACIÓN E INTEGRACIÓN DE UN SISTEMA GEORREFERENCIADO.
}

\section{MANAGEMENT OF ADDRESSES AND ROAD: DIFFICULTIES FOR THE GENERATION AND INTEGRATION OF A GEOREFERENCED SYSTEM.}

\author{
Luis Copano Ortiz \\ Instituto de Estadística y Cartografía de Andalucía \\ luis.copano@geografosdeandalucia.org
}

Recibido: marzo, 2014.

Versión final aceptada: mayo, 2014.

PALABRAS CLAVE: Direcciones, viario, georreferenciación, Inspire, EURADIN.

KEYWORDS: Addresses, road, georeferencing, Inspire, EURADIN.

RESUMEN

La consecución de un sistema integrado de direcciones hará posible geolocalizar todo edificio o lugar susceptible de ser habitado o de acoger una actividad económica, permitiendo disponer de información estadística con desagregación a nivel de portal. El futuro "Gestor de Direcciones Postales" está diseñado para que en los registros administrativos la información sobre dirección solo pueda relacionarse con una de las almacenadas en la base de datos espacial. Según el estudio realizado por el proyecto EURADIN, la disponibilidad de este sistema va a permitir una importante reducción en los gastos derivados de la gestión de direcciones obteniéndose un valor añadido de 60.000 millones de euros anuales, lo que ha derivado en un mayor interés por parte de las administraciones y de sectores económicos asociados a las nuevas tecnologías.

\section{ABSTRACT}

The achievement of an integrated system of addresses will make possible geolocate any building or place likely to be inhabited or to host an economic activity, allowing for statistical information with disaggregation to level of portal. The future "Manager of Postal Addresses" is designed for that in the administrative records the address information only can interact with one of the stored in the spatial database. According to a study by EURADIN project, the availability of this system is going to allow a significant reduction in the costs of managing addresses obtaining an added value of 60,000 million euros per year, which has resulted in an increased interest on the part of public administration and economic sectors associated with new technologies.

ISSN: 0212-8594 ISSN-e: 2340-2776. № DOI: http://dx.doi.org/10.12795/rea.2014.i31.03

REA 31 (2014): 54-84

http://www.publius.us.es/estudios_andaluces 


\section{INTRODUCCIÓN.}

El debate sobre un modelo único de direcciones se revitaliza con la aprobación, por el Parlamento Europeo y el Consejo, de la Directiva Inspire(2007), "cuyo principal objetivo es fijar normas generales con vistas al establecimiento de una infraestructura de información espacial en la Comunidad Europea", siendo incorporada al ordenamiento jurídico español a través de la Ley 14/2010, de 5 de julio, sobre las infraestructuras y los servicios de información geográfica en España (LISIGE).

Conviene destacar la labor impulsada por el proyecto europeo EURADIN (European Addresses Infrastructure) financiado con fondos eContentplus con participación de más de 30 organismos públicos y privados de 16 países europeos, coordinados por la Comunidad Foral de Navarra, cuyo principal objetivo ha sido el de contribuir a la armonización de las direcciones en Europa, proponiendo una solución que permitiera su interoperabilidad y facilitara su difusión, reutilización y explotación (Valentín, A., 2011).

Para asegurar que las infraestructuras de datos espaciales sean compatibles e interoperables, Inspire ${ }^{1}$ exige que se adopten Normas de Ejecución comunes (Implementing Rules) específicas para las siguientes áreas: metadatos, conjuntos de datos, servicios de red, datos y servicios de uso compartido y seguimiento e informes. La implementación técnica de estas normas de obligado cumplimiento se realiza mediante las Guías Técnicas o Directrices (Technical Guidelines), documentos técnicos basados en estándares y normas Internacionales.

Para el tema que nos ocupa, nos interesan especialmente las guías técnicas de los datos espaciales referidos a direcciones, nombres geográficos, redes de transporte y unidades administrativas, todos ellos encuadrados en el anexo I de Inspire. Además, para cada uno de estos temas, el Consejo Directivo de la Infraestructura de Información Geográfica de España (CODIIGE) ha creado un Grupo Técnico de Trabajo (GTT) específico cuya misión es la implementación de cada tema conforme al Reglamento (UE) № 1089/2010 de interoperabilidad de los conjuntos y los servicios de datos por parte de las Administraciones Públicas españolas y ayudar a sus órganos y organismos a conseguir su cumplimiento.

De esta forma, el GTT sobre direcciones y callejero, coordinado por el Instituto Nacional de Estadística, y en el que participan la Dirección General del Catastro (DGC), el Instituto Geográfico Nacional (IGN), la Sociedad Estatal Correos y Telégrafos, la Federación Española de Municipios y Provincias (FEMP) y Comunidades Autónomas como Andalucía, Galicia, La Rioja o Navarra, ha tomado como referencia el documento "Modelo de Direcciones de la Administración General del Estado v.2" que establece un

\footnotetext{
${ }^{1}$ Toda la documentación y noticias relacionadas con Inspire es accesible por medio de su web: http://inspire.ec.europa.eu/

ISSN: 0212-8594 ISSN-e: 2340-2776. № DOI: http://dx.doi.org/10.12795/rea.2014.i31.03 
modelo único e integrado de direcciones normalizadas y georreferenciadas con el objetivo básico de llegar a ser utilizado por todos los órganos de la AGE en cualquier actividad relacionada con el tema de direcciones.

\section{COMPONENTEGEOGRÁFICO DE DIRECCIÓN Y VIARIO.}

En la sociedad tecnológica actual las bases de datos espaciales han adquirido una mayor relevancia por la capacidad que ofrecen a instituciones, empresas e incluso personas, para geolocalizar puntos de interés o realizar análisis territoriales más o menos complejos. Esta "democratización" de la información geoespacial, que acerca al ciudadano a un ingente volumen de datos: bases de datos espaciales, planos, mapas, fotografías y otros documentos georreferenciados, con un gran nivel de detalle, de forma rápida y sencilla, se dispara con la irrupción de la aplicación Google Earth que la empresa Google Inc. lanzó a mediados de 2005. En este contexto tecnológico, Inspire trata de concentrar todos estos avances para permitir que la información geográfica esté normalizada, cumpla con unos determinados niveles de calidad y sea interoperable.

Se estima que entorno al $90 \%$ de los datos existentes en las Bases de Datos Corporativas son susceptibles de ser georreferenciados mientras que la realidad que nos encontramos es que para el potencial existente, la difusión de la tecnología de los Sistemas de Información Geográfica (SIG) es mejorable en la administración y muy escasa en empresas privadas ajenas al sector geoespacial (Anguix, A., 2005). Una gran parte de los registros almacenados en bases de datos alfanuméricas poseen un campo que informa sobre la dirección, por lo que la georreferenciación de los mismos solo necesita de un sistema de información sobre direcciones que permita la relación entre los elementos de cada base de datos y, de esta forma, aporte la dimensión geográfica mediante unas coordenadas.

El concepto de dirección está íntimamente relacionado con la dimensión espacial de un objeto geográfico aunque su definición es más compleja de lo que a priori pueda parecer. Creo necesario partir de la definición aportada por el diccionario de la lengua española (DRAE), ya que aunque desde una visión general de su terminología, ofrece unas pautas que deben ser tenidas en cuenta. De esta forma, considerando sus distintas acepciones, podríamos definir el concepto de domicilio (concepto al que nos deriva la búsqueda de dirección) como la morada en la que alguien habita o se hospeda y legalmente se considera establecido para el cumplimiento de sus obligaciones y el ejercicio de sus derechos. También define lo que sería el "domicilio social" referido, en este caso, a una empresa o establecimiento.

Por otro lado, una dirección queda definida, en el anexo I de Inspire, como la "localización de las propiedades basada en identificadores de direcciones, por ejemplo, el nombre de la vía pública, el número de la vivienda, el código postal". Esta definición

ISSN: 0212-8594 ISSN-e: 2340-2776. № DOI: http://dx.doi.org/10.12795/rea.2014.i31.03 
es bastante ambigua y poco precisa en relación con el concepto de propiedad, por ello, la especificación técnica (Data Specification) sobre direcciones la aclara y amplía refiriéndose a la "identificación de la ubicación fija de una propiedad, por ejemplo: parcela de terreno, edificio, parte del edificio o el modo de acceso, por medio de una composición estructurada de nombres geográficos e identificadores". Además, añade que en algunos países objetos como el mobiliario urbano, las estaciones de bombeo de agua o los puntos de amarre poseen direcciones, siendo denominados todos como "objetos direccionables".

En definitiva, el concepto de dirección queda definido por una componente espacial (su localización) y otra de tipo descriptivo (composición estructurada de nombres geográficos, normalmente jerarquizada, e identificadores) sobre un objeto geográfico; por lo general, estos objetos direccionables son elementos de tipo puntual como edificaciones aunque pueden ser otro tipo de abstracción de la realidad como parcelas de terreno, que serían de tipo poligonal.

Por tanto, podemos tener una dirección para objetos direccionables de tipo puntual (edificios, miradores) y zonal (lugares de acampada, parcelas) ya que el propósito de las direcciones es variado: reparto de paquetería y correo postal, intervención en situaciones de emergencia, identificación de puntos de interés, localización de la población para gestión demográfica, asistencial o tributaria, etc. En este sentido, en el Gestor de Direcciones de Navarra (GDN) se distinguen cuatro componentes: direcciones postales, puntos de interés, toponimia y red viaria, que permitirán funciones de localización, visualización, conectividad, navegabilidad, etc.

No obstante, parece más apropiado que una dirección esté definida geográficamente por un objeto espacial cuya abstracción del mundo real sea de tipo puntual, por lo que aquellos elementos de tipo zonal deben formar parte de la composición estructurada de nombres geográficos de la definición de dirección que ofrece Inspire.

Un elemento de gran interés a incorporar es la red viaria ya que, además de formar parte de la composición estructurada de nombres geográficos (componente descriptiva), permitirá hacer efectiva la funcionalidad de conectividad y navegación entre direcciones, permitiendo los análisis de distancia y accesibilidad, costes de transporte, etc. (componente espacial).

Pero ¿qué entendemos por red viaria? La mayor parte de definiciones asemejan este concepto al de red de carreteras, si bien algunas (p.e. DRAE) matizan que se denomina red viaria al conjunto de caminos y carreteras. Por su parte, Inspire recoge en su anexo I la temática sobre redes de transportes: por carretera, ferrocarril, aéreo y marítimofluvial, con sus correspondientes infraestructuras, por lo que parece olvidarse de las conexiones urbanas y de las interurbanas como los caminos, si bien el término "road"posee diferentes acepciones en la lengua inglesa, que van desde carretera,

ISSN: 0212-8594 ISSN-e: 2340-2776. № DOI: http://dx.doi.org/10.12795/rea.2014.i31.03

REA 31 (2014): 54-84

http://www.publius.us.es/estudios_andaluces 
pasando por camino, senda, vía y calle; por otro lado, LISIGE incluye en este mismo apartado a la red de caminos y vías pecuarias para esclarecer la ambigüedad de la documentación original de Inspire, por lo que podríamos considerar que todas las vías interurbanas estarían consideradas dentro de la red viaria.

¿Y qué ocurre con la red viaria urbana? Por ejemplo, el GTT sobre direcciones y callejero considera a todo el viario urbano dentro de sus objetivos y análisis a pesar de que LISIGE no hace mención expresa en sus anexos a la red viaria urbana, existiendo un grupo específico para las redes e infraestructuras de transporte.

En el presente artículo englobaremos dentro del concepto de red viaria tanto la red urbana, que queda definida por aquellos viales que se sitúan dentro de la clasificación de suelo urbano realizado por algún instrumento de planeamiento urbanístico, como la red interurbana, en la que predominan los recorridos de larga duración y motorizados.

\section{INSPIRE: GUÍA TÉCNICA SOBRE DIRECCIONES EN EL ÁMBITO EUROPEO.}

La guía técnica sobre direcciones (Data Specification on Addresses) es el documento de referencia para la consecución de la interoperabilidad sobre direcciones en el ámbito europeo. A pesar de que todos los sistemas de direcciones nacionales, regionales o locales comparten objetivos, propiedades y conceptos similares existen diferencias en las normas formales e informales, reglas, esquemas y modelos de datos.

En la figura 1 se observa una dirección física que será registrada de forma diferente en función del modelo de datos de direcciones específico de cada estado miembro. Por lo general, se ofrecerá una descripción jerárquica desde el nombre del país o región, municipalidad, nombre de la vía, número de edificio y vivienda.

La dirección (Address) es un objeto espacial que identifica la ubicación fija de una propiedad de forma inequívoca (ver figura 2), por medio de un identificador: número de dirección o nombre de edificio (Locator) y una posición geográfica (Position). Para su identificación sin ambigüedades en un contexto más amplio, se hace necesaria la utilización de los componentes de dirección (Address Component) que definen su ubicación dentro de un área geográfica determinada. El esquema de aplicación define cuatro subclases de componentes de dirección: el nombre de la vía (Through fare Name); el nombre del área de dirección (Address Area Name) que sin ser una unidad administrativa, si posee un nombre propio e identificable como, por ejemplo, un núcleo de población; el descriptor postal (Postal Descriptor); y el nombre de la unidad administrativa (Administrative Unit Name) a la que pertenece una dirección.

Es recomendable que la posición geográfica de una dirección sea la ubicación real de la puerta de entrada o, al menos, el punto central del edificio a la que la dirección está

ISSN: 0212-8594 ISSN-e: 2340-2776. № DOI: http://dx.doi.org/10.12795/rea.2014.i31.03

REA 31 (2014): 54-84

http://www.publius.us.es/estudios_andaluces 
asociada, procurando ofrecer la máxima precisión geográfica posible. También se ofrece la posibilidad de dar las coordenadas del punto central de alguno de los componentes de dirección, dando prioridad al componente que permita determinar la posición con mayor exactitud (siendo recomendable no superar el nivel del "through fare name").

Inspire permite que una dirección posea más de una posición, por ejemplo la ubicación del edificio y el punto de entrega postal (buzón de correo) o el punto del eje de una calle desde el que sea más factible acceder a la dirección, siendo necesario aclarar el tipo de posición utilizado. No obstante, sería recomendable evitarlo en lo posible para no generar duplicidades.

Figura 1. Ejemplo de dirección.

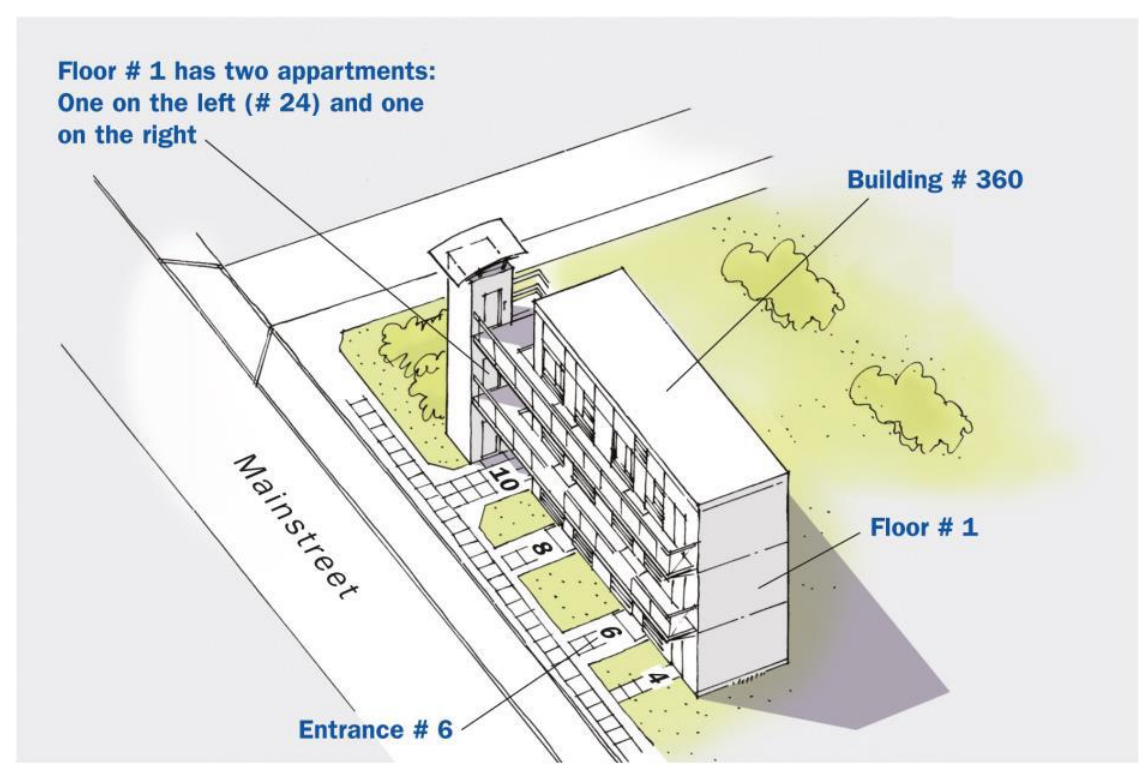

Fuente: INSPIRE Data Specification on Addresses (2014).

El propósito del elemento "Address Locator" es la distinción de una dirección respecto a sus vecinas, por lo que el tipo de dato "Address Locator" posee los atributos "designator", "name" y "level", siendo necesario que al menos posea un identificador de dirección. Una dirección en España bien podría ser la siguiente: “Calle Alta, no 41, BI. 1 5A, 29200 Antequera (Málaga)" por lo que para este caso tendríamos varios identificadores (designator) de dirección (la numeración del edificio, el bloque, la planta y la puerta) que se corresponderían con diferentes niveles (level). En algunas ocasiones, una dirección puede poseer un nombre específico (name), siendo muy habitual en las zonas de hábitat diseminado (Cortijo de la Plata, Casa de las Flores), lo que vendría a complementar o ser una alternativa al identificador.

ISSN: 0212-8594 ISSN-e: 2340-2776. № DOI: http://dx.doi.org/10.12795/rea.2014.i31.03 
Luis Copano Ortiz

Gestión de direcciones y viarios: dificultades para la generación e integración de un sistema georreferenciado

Figura 2. Diagrama de clases UML. Esquema de aplicación sobre Direcciones.

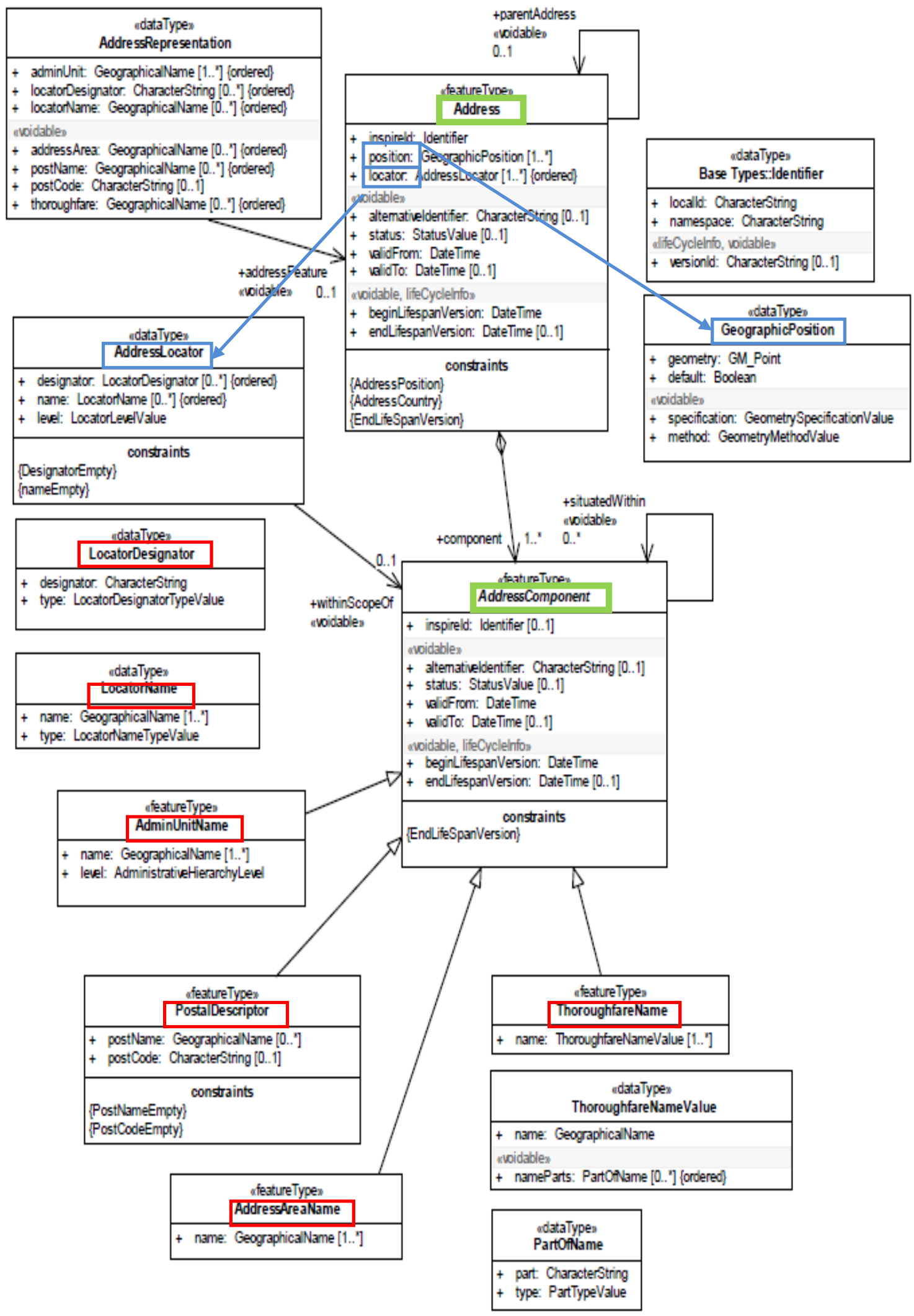

Fuente: INSPIRE Data Specification on Addresses (2014).

ISSN: 0212-8594 ISSN-e: 2340-2776. № DOI: http://dx.doi.org/10.12795/rea.2014.i31.03

REA 31 (2014): 54-84

http://www.publius.us.es/estudios_andaluces 
Una de las propiedades más características de los identificadores de dirección es que tienden a ser únicos dentro de un determinado ámbito o componente de dirección, como por ejemplo una calle, un núcleo de población o un código postal, de ahí la importancia que existe en que estén correctamente relacionados.

Los componentes de dirección tienden a estar jerarquizados siendo elementos del mundo real independientes a las direcciones aunque necesarios para su correcta identificación; así, el nombre de las unidades administrativas (Administrative Unit Name), integrado como una temática del anexo I de Inspire, debe relacionarse con las direcciones, que deben pertenecer a áreas delimitadas donde la administración nacional, regional o local ejerza su jurisdicción (González, A., 2011). Por otro lado, existen otras delimitaciones o límites aproximados (Address Area Name) que, sin ser unidades administrativas, permiten precisar la ubicación de una dirección evitando la ambigüedad de la misma. En España, tendríamos las entidades recogidas en el nomenclátor de entidades de población: entidades colectivas, entidades singulares, núcleos de población y diseminados; así como las entidades locales menores (que podrían incluirse en el grupo anterior siempre y cuando dispongan de una delimitación precisa), pero también otras delimitaciones interiores a los ámbitos urbanos como distritos o barrios.

El concepto y las propiedades de los descriptores postales (Postal Descriptor) nacionales difieren entre países, si bien, por lo general, representa una subdivisión interna de municipios cuyas direcciones normalmente están asociadas a una oficina, zona o ciudad con la finalidad de la distribución del reparto postal. En otras ocasiones, no son más que un atributo alfanumérico de una dirección que debido a su utilización en diversos sectores y aplicaciones se ha mantenido vigente.

En cuanto al componente del nombre de la vía (Through fare Name) y con la intención de cumplir con el estándar S.42 de la Universal Postal Union (UPU), el esquema de aplicación permite, opcionalmente, subdividir el nombre de la vía en tipo (Type), prefijo del nombre (Name Prefix), nombre (Name) y un calificador (Qualifier). El interés de esta disgregación no es otro que permitir el ordenamiento alfabético de los viales, mejorar las búsquedas semánticas o el análisis de nombres con error en su escritura.

\section{LA GESTIÓN DE DIRECCIONES EN ESPAÑA: HACIA UN MODELO UNIFICADO.}

Como ya se ha comentado en la parte introductoria del presente artículo, el Consejo Directivo de la Infraestructura de Información Geográfica de España (CODIIGE) creó en el año 2012 el Grupo Técnico de Trabajo (GTT) sobre direcciones y callejero (según los grupos temáticos del Anexo I de LISIGE), desmarcándose de la Directiva Inspire que consideraba como temas independientes, aunque relacionados, el de direcciones y el de transportes (grupo en el que se insertarían los callejeros). Entre los objetivos del grupo estarían el de desarrollar un modelo de datos de direcciones y de callejero de

ISSN: 0212-8594 ISSN-e: 2340-2776. № DOI: http://dx.doi.org/10.12795/rea.2014.i31.03

REA 31 (2014): 54-84

http://www.publius.us.es/estudios_andaluces 
referencia para el intercambio de información entre instituciones (sistema de flujos) según los requisitos de Inspire.

No obstante, la iniciativa para la definición de un Modelo de Direcciones ya había surgido dentro de la Administración General del Estado (AGE) por la necesidad de establecer un modelo de direcciones normalizadas y georreferenciadas de los inmuebles a nivel nacional, con una definición correcta e inequívoca, que permitiera el intercambio efectivo de información. Esta primera versión del modelo (MDAGE v1) se presentaría públicamente en las primeras Jornadas Ibéricas de las Infraestructuras de Datos Espaciales (Lisboa, 2010) tomando como referencia el modelo de datos del proyecto SIG_PT (Sistema Integrado de Población y Territorio) desarrollado por el Grupo Técnico de Trabajo de la AGE y en el que intervinieron el Instituto Nacional de Estadística (INE), la Dirección General del Catastro (DGC), la Agencia Estatal de Administración Tributaria (AEAT), la Sociedad Estatal de Correos y Telégrafos y el Instituto Geográfico Nacional (IGN). Posteriormente, cuando comenzaron los trabajos para la extensión del modelo hacia una cobertura de red viaria se detectó la necesidad de revisar y puntualizar determinadas características del mismo, dando como resultado una evolución en el modelo que daría lugar a una segunda versión (MDAGE v2).

Es importante tener en cuenta que la gestión de direcciones en España hasta la elaboración del documento "Modelo de Direcciones de la Administración General del Estado v.2" adolecía de importantes deficiencias en cuanto a la coordinación interadministrativa y a la normalización y georreferenciación de las direcciones.

\subsection{DISPERSIÓN DE ESFUERZOS SOBRE DIRECCIONES.}

Por un lado, la Ley $7 / 1985$, reguladora de las Bases del Régimen Local establecía que los ayuntamientos eran los encargados de la gestión (informatizada) de los Padrones municipales debiendo contener, de forma obligatoria, información sobre el domicilio habitual; a su vez, los Ayuntamientos debían remitir al INE sus datos a fin de que pudiera llevarse a cabo la coordinación entre los Padrones de todos los municipios con el fin de subsanar posibles errores y evitar duplicidades, realizando las comprobaciones oportunas y comunicando a los Ayuntamientos las modificaciones efectuadas para que los datos sirviesen de base para la elaboración de estadísticas de población a nivel nacional y para que las cifras resultantes se declarasen como oficiales.

Posteriormente, se publica el Real Decreto 1690/1986 por el que se aprueba el Reglamento de Población y Demarcación Territorial, estableciendo que los ayuntamientos deberán actualizar la nomenclatura y rotulación de las vías públicas, la numeración de los edificios, la relación de entidades y núcleos de población y la división en secciones censales del municipio; sin embargo, poco se aportará en

ISSN: 0212-8594 ISSN-e: 2340-2776. № DOI: http://dx.doi.org/10.12795/rea.2014.i31.03

REA 31 (2014): 54-84

http://www.publius.us.es/estudios_andaluces 
relación a cómo realizar dicha gestión, siendo necesario esperar al Real Decreto 2612/1996, por el que se modifica el reglamento anteriormente mencionado, siendo muy relevante en cuanto a postulados teóricos (en la práctica, la falta de medios técnicos, económicos o de personal dieron como resultado una gestión alfanumérica del dato) ya que establece que los ayuntamientos deberán mantener la correspondiente cartografía o, en su defecto, la referencia precisa de las direcciones postales con la cartografía elaborada por la Administración competente.

Con el objetivo de ofrecer un documento de referencia para la gestión y revisión del Padrón municipal que diera respuesta al artículo 60 del Real Decreto 2612/1996, y evitar la dispersión en la aplicación práctica de sus postulados por parte de los ayuntamientos, se publicó la Resolución de 9 de abril de 1997, por la que se dictaban instrucciones técnicas referidas, entre otras temáticas, a la definición de las unidades poblacionales (entidad colectiva, entidad singular, núcleo de población y diseminado), revisión de los callejeros, concepto de vías y pseudovías, y numeración de los edificios.

Esta visión sesgada del concepto de dirección y callejero, con la importante ausencia de la componente espacial o geográfica y el punto de mira puesto en las direcciones con población empadronada, ha limitado en gran medida una gestión eficiente del territorio, tanto en lo relativo a direcciones y viarios, como en el adecuado manejo de las entidades zonales (unidades poblacionales, secciones censales, códigos postales, etc.). De esta forma, la labor realizada por la Dirección General del Catastro, en colaboración con las diferentes Administraciones, entidades y corporaciones públicas (principalmente los ayuntamientos), ha permitido disponer de una descripción catastral de los bienes inmuebles que comprende sus características físicas, económicas y jurídicas, entre las que se encuentran su localización, la referencia catastral, la superficie, el uso o destino, la clase de aprovechamiento, el estado de las construcciones, la representación gráfica, el valor y el titular catastral junto a su número de identificación fiscal y, lo que es más importante, un tratamiento homogéneo de la información para todo el territorio nacional.

Entre las obligaciones de representación gráfica y recogida de información alfanumérica de la cartografía catastral no se encuentran los ejes viales o la denominación de los mismos, así como tampoco la existencia de un portalero por lo que, a pesar de presentar dicha información, la descoordinación con las direcciones del Padrón o de los callejeros municipales ha generado incongruencias, principalmente en cuanto a la numeración de los portales.

ISSN: 0212-8594 ISSN-e: 2340-2776. № DOI: http://dx.doi.org/10.12795/rea.2014.i31.03 
Figura 3. Cartografía catastral.

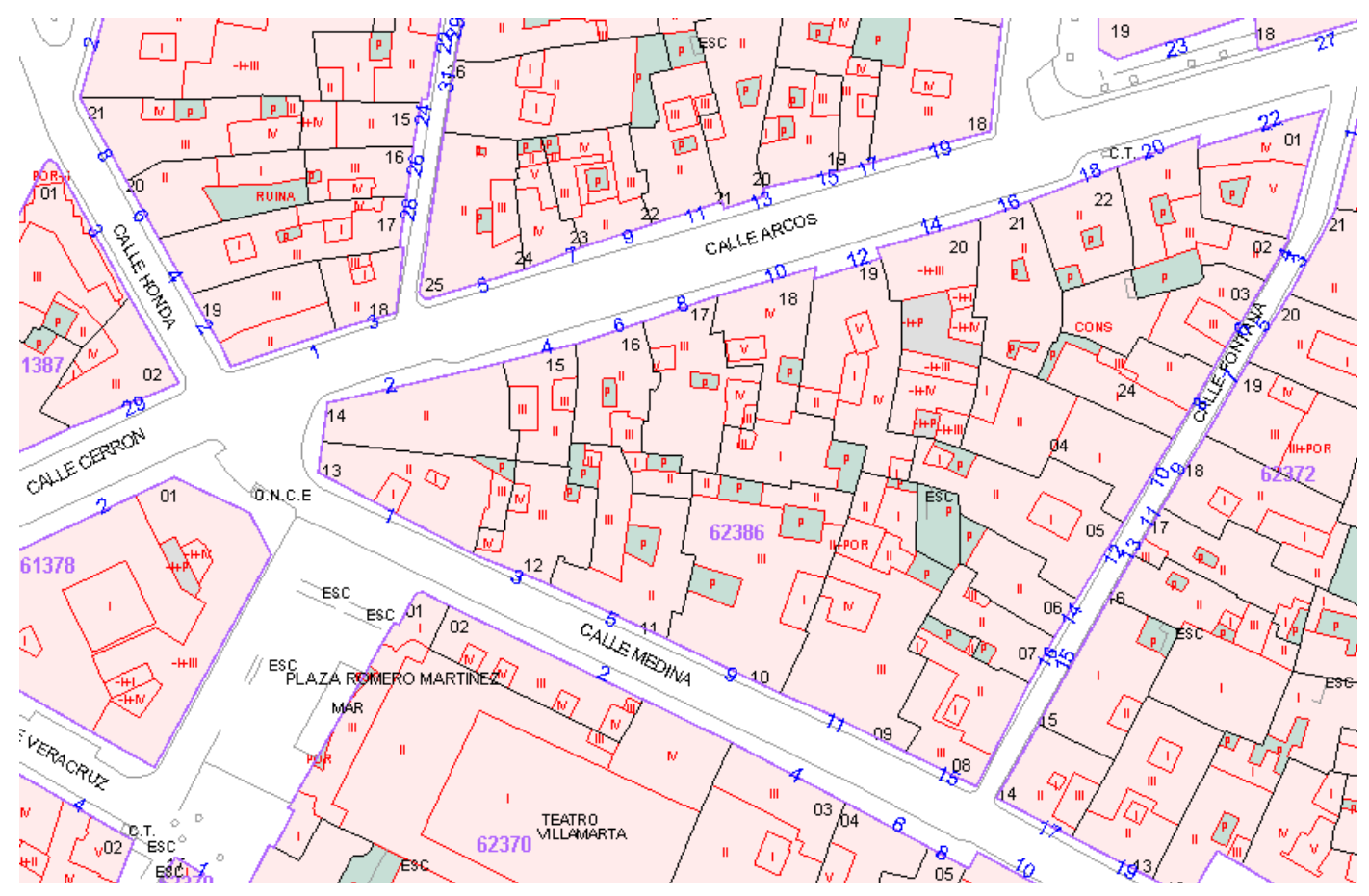

Fuente: Sede Electrónica del Catastro (2014).

\subsection{CARTOCIUDAD: MODELO DE INTEGRACIÓN DE CALLEJERO.}

En el año 2005, con el objetivo de conseguir ser la base de datos oficial de la AGE de red viaria con continuidad topológica de SIG, se comienzan a definir el modelo de datos y las especificaciones técnicas para la elaboración del producto cartográfico CartoCiudad. Liderado y coordinado por el Instituto Geográfico Nacional (IGN), se pretende armonizar e integrar los datos oficiales del IGN, la Dirección General del Catastro (DGC), el Grupo Correos y el Instituto Nacional de Estadística (INE), todo ello canalizado mediante la firma de Convenios de colaboración.

Fruto de los trabajos de definición y análisis del modelo de datos conceptual de callejero, se redactó el documento de referencia denominado "Especificaciones de CartoCiudad" ${ }^{2}$ cuyo núcleo central son los fenómenos de vial, tramo y portal (ver figura 4). De esta forma, en orden ascendente tendríamos que todo portal debe pertenecer a un solo tramo y todo tramo a alguna vía y, en orden descendente, todo vial estará compuesto de al menos un tramo y cualquiera de los tramos podrá estar relacionado con uno, muchos o ningún portal. Además, se incorpora en el modelo la tabla "tramo_vial" que nos permite conocer la relación de tramos que pertenecen a cada vial y la existencia de tramos que forman parte de más de un vial.

\footnotetext{
${ }^{2}$ La última versión publicada en la web (http://www.cartociudad.es/portal/) es la 10.1 con fecha de junio de 2010.
}

ISSN: 0212-8594 ISSN-e: 2340-2776. № DOI: http://dx.doi.org/10.12795/rea.2014.i31.03 
Figura 4. Modelo de aplicación de Carto Ciudad simplificado.

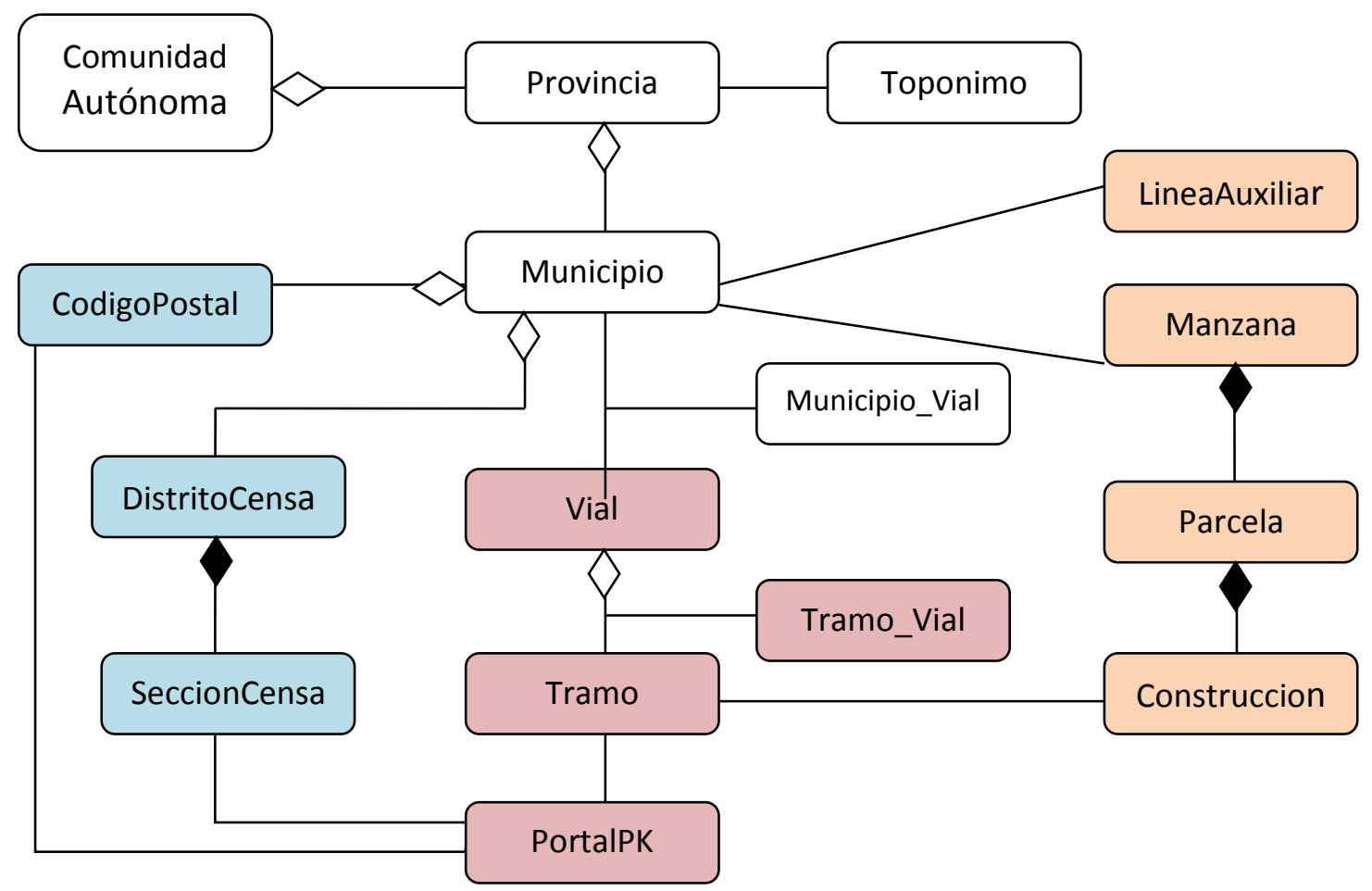

Fuente: Elaboración propia a partir de Especificaciones de CartoCiudad (2013).

Otros fenómenos existentes serían los relativos a unidades administrativas (municipio, provincia y Comunidad Autónoma) relacionados entre sí de forma jerárquica y respecto a los viales mediante una tabla intermedia denominada "municipio_vial" cuyo objetivo es conocer todos los viales de un municipio y el municipio al que pertenece un vial, teniendo en cuenta que ciertos viales interurbanos discurren por más de un término municipal.

Los códigos postales y los distritos censales se relacionarían de forma directa con los fenómenos de portal y municipio; así, cada portal se integrará en un solo registro de los fenómenos anteriores, y cada descriptor postal y distrito solo podrá pertenecer a un municipio. En cuanto a las secciones censales ${ }^{3}$, se trata de subdivisiones de los distritos censales.

\footnotetext{
${ }^{3}$ Partición del término municipal caracterizada por estar preferentemente definida mediante límites fácilmente identificables, tales como accidentes naturales del terreno, construcciones de carácter permanente y viales; y tener un tamaño entre 1.000 y 2.500 residentes, excepto en el caso que el municipio completo tenga una población inferior.
}

ISSN: 0212-8594 ISSN-e: 2340-2776. № DOI: http://dx.doi.org/10.12795/rea.2014.i31.03 
También se incorporan fenómenos de tipo urbano y catastral ${ }^{4}$ como son líneas auxiliares, manzanas, parcelas y construcciones. Toda construcción debe pertenecer a una parcela y esta, a su vez, a una manzana que se engloba dentro de un único municipio. Las líneas auxiliares, por su parte, se relacionan directamente con los municipios y en ningún caso con algún otro tipo de fenómeno ya que su función es la de ofrecer salidas cartográficas.

Por último, nos encontramos con el fenómeno toponimia, de especial interés en las zonas no urbanas ya que aportan información que complementa a las direcciones y que permitirá realizar búsquedas de localizaciones imprecisas.

Para la obtención de los ejes viales urbanos se utilizan datos provenientes del Catastro y de callejeros y bases cartográficas autonómicas y locales para su armonización, integración y la configuración de una estructura de red topológica, conectándose con la red interurbana (autopistas, autovías, carreteras, caminos, pistas y sendas) procedentes de la Base Topográfica Nacional a escala 1/25.000 (BTN25) o de la Base Cartográfica Numérica a escala 1/25.000 (BCN25), conformándose una red continua para todo el territorio nacional.

En cuanto a la denominación de los nombres de vías, se recurre a distintas fuentes: por un lado, todo aquel viario en el que exista población empadronada toma como fuente de referencia el Padrón de habitantes del INE, para los viales interurbanos se recurre al Ministerio de Fomento para la Red de Carreteras del Estado y a los organismos competentes en la materia de las distintas Comunidades Autónomas o las diputaciones para el resto de la red de carreteras y, por último, para el resto del viario urbano e interurbano se obtiene la información del Catastro y de los callejeros autonómicos y locales.

El siguiente paso sería complementar la red viaria con información geográfica de portal, que se incorpora para poder localizar direcciones (a nivel de aproximación postal) y calcular rutas; así como cartografía urbana como son manzanas, parcelas, construcciones, toponimia urbana y líneas auxiliares que ofrecen un fondo urbano preciso y actualizado para la generación de salidas cartográficas y la configuración de servicios web de mapas.

Correos aporta el listado completo de códigos postales y su relación con las direcciones y núcleos de población; los distritos y secciones censales se incorporan de la base de datos del INE; y del IGN se obtienen, además, las líneas límites administrativas, y la toponimia de los Nomenclátores Geográficos.

\footnotetext{
${ }^{4}$ Estos fenómenos no son propios del modelo de callejero sino que provendrían de la temática sobre parcelas catastrales del anexo I de Inspire, por lo que no se ofrece mantenimiento desde este proyecto.
}

ISSN: 0212-8594 ISSN-e: 2340-2776. № DOI: http://dx.doi.org/10.12795/rea.2014.i31.03

REA 31 (2014): 54-84

http://www.publius.us.es/estudios_andaluces 
Figura 5. Flujos para la actualización de CartoCiudad.

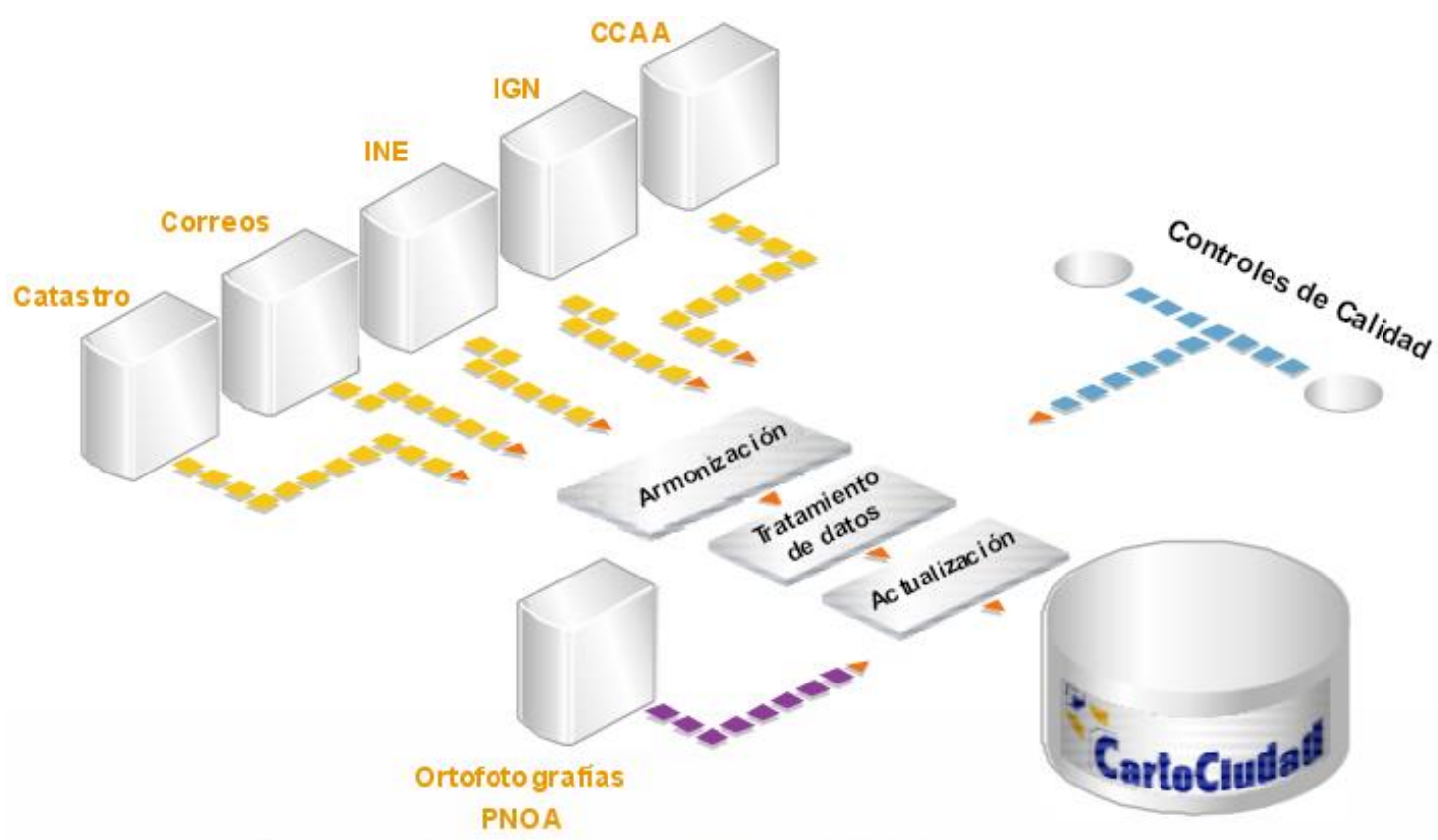

Fuente: 'Territorial 2010', Conferencia sobre Sistemas de Información territorial (2010).

Las especificaciones técnicas del producto CartoCiudad ofrecen información de interés más allá de la generación de un modelo de datos de callejero. Alcanza el ámbito práctico en la producción y mantenimiento de los datos aportando criterios para mapear los diferentes tipos de fenómenos del modelo en su apartado 7.2 relativo a los procesos de producción.

En cuanto al mantenimiento de los datos, es el apartado 8 de las especificaciones el que da las pautas para la inserción, eliminación y modificación de elementos. La representación de un elemento a lo largo del tiempo se hace mediante el uso de múltiples registros (manteniendo el mismo identificador) de los que sólo uno está vigente, y el resto son históricos o en proceso de actualización. Esta información se almacena en el atributo "estado", que puede tomar uno de los siguientes valores: alta, baja, vigente e histórico.

\subsection{INICIATIVAS AUTONÓMICAS DE COOPERACIÓN INTERADMINISTRATIVA.}

La experiencia acumulada en materia de direcciones y callejero por parte del Instituto de Estadística y Cartografía de Andalucía (IECA) ha propiciado la generación del producto Callejero Digital de Andalucía Unificado $(\mathrm{CDAU})^{5}$, sirviendo de apoyo o nexo de unión entre diferentes actividades estadísticas y cartográficas en Andalucía.

\footnotetext{
${ }^{5}$ Para conocer sus servicios interoperables, productos cartográficos o utilidades está disponible la web del proyecto: http://www.juntadeandalucia.es/institutodeestadisticaycartografia/callejero/index.htm.
}

ISSN: 0212-8594 ISSN-e: 2340-2776. № DOI: http://dx.doi.org/10.12795/rea.2014.i31.03 
En el año 2006, se comienzan los trabajos para la elaboración de un callejero digital que diera cobertura a todos los núcleos de población andaluces, por lo que se adjudica un concurso de asistencia técnica para la generación y mantenimiento del mismo que acabaría a mediados de 2010. Se hacía necesario entonces la creación de un modelo de mantenimiento continuado (Ríos, J., 2010) que cumpliera con dos objetivos ya mencionados por Inspire: por un lado, que la información relativa a viales y portales se levantara una sola vez (dato único) y que el mantenimiento de los datos se realizara por el organismo competente a la mayor resolución posible (actualización descentralizada).

La idea principal sobre la que pivota el CDAU es la colaboración interadministrativa por lo que no se trata de un producto exclusivo de la Junta de Andalucía; de este modo, se han firmado convenios específicos con la AGE (CNIG), con cada una de las Diputaciones Provinciales de Andalucía y con la Federación Andaluza de Municipios y Provincias (FAMP) al que se pueden adherir cada uno de los municipios andaluces.

Según el esquema de mantenimiento del dato, los editores 1 serán aquellos municipios o diputaciones (o cualquier organismo que tenga competencia en la gestión de determinados viales, como por ejemplo el Ministerio de Fomento para la Red de Carreteras del Estado) que posean sus propios callejeros con un modelo de datos acorde con las necesidades mínimas para la adecuación con el modelo de CDAU y, además, realicen un mantenimiento continuado de la información por lo que periódicamente se establecerá la sincronización de aquellos elementos modificados desde la última actualización con la base de datos centralizada de CDAU.

Por su parte, a los editores 2 se les proporcionará una plataforma en línea para el mantenimiento de la información; se trata de aquellos municipios o provincias, principalmente, que no posean un callejero digital propio y ejecuten las actualizaciones directamente sobre la base de datos centralizada.

Las actualizaciones realizadas tanto por los editores 1 como por los editores 2 deberán ser revisadas por un equipo técnico de trabajo del IECA (para evitar duplicidades, comprobar que no existen errores en la inclusión de datos alfanuméricos o en la topología y exactitud posicional de la geometría) antes de ser validadas en el sistema y formar parte de la base de datos unificada.

Por otro lado, se sitúan los editores 3 , formados por los organismos e instituciones que en su actividad diaria hacen uso del CDAU, y los editores 4, que englobaría a toda la ciudadanía, lo que permite ofrecer cauces de participación ciudadana. Ambos, tendrán la posibilidad de reportar notificaciones sobre posibles errores o incoherencias de la información existente que será enviada a las bandejas de incidencias de los editores 1 y 2 (según corresponda) para su resolución.

ISSN: 0212-8594 ISSN-e: 2340-2776. № DOI: http://dx.doi.org/10.12795/rea.2014.i31.03 
Gestión de direcciones y viarios: dificultades para la generación e integración de un sistema georreferenciado

Figura 6. Primera propuesta del Modelo de mantenimiento del CDAU.

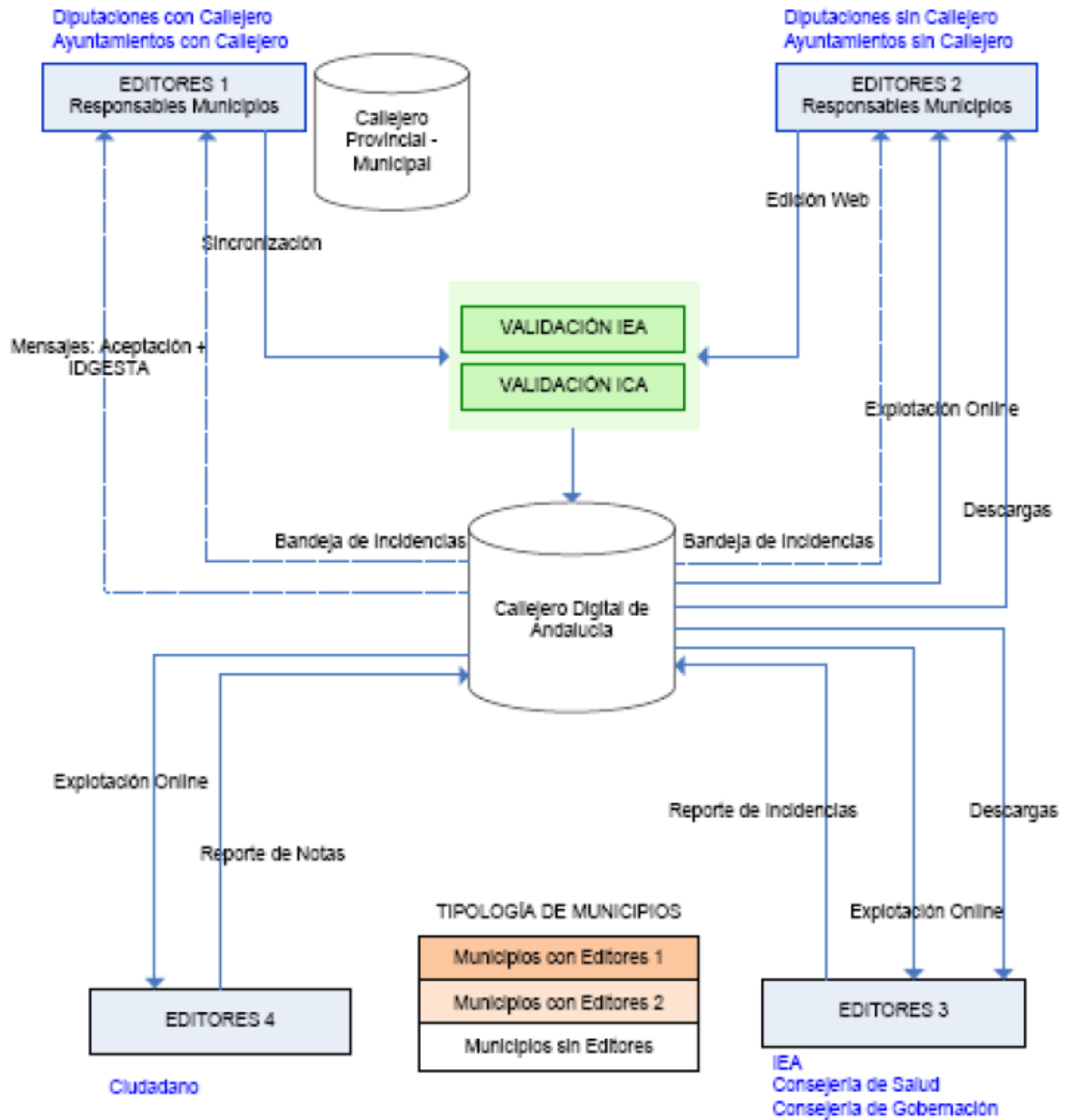

Fuente: XVII Jornadas de Estadísticas de las Comunidades Autónomas (2010).

La elaboración del modelo de datos de CDAU ha tenido como base de referencia conceptual las especificaciones de datos y catálogo de fenómenos de CartoCiudad y la guía técnica sobre direcciones de Inspire, teniendo como objetivo principal, además del cumplimiento de la normativa en la materia, la consecución del consenso entre los organismos e instituciones (IGN, distintas Consejerías de la Junta de Andalucía interesadas en la temática y entidades locales, principalmente ayuntamientos $\mathrm{y}$

ISSN: 0212-8594 ISSN-e: 2340-2776. № DOI: http://dx.doi.org/10.12795/rea.2014.i31.03

REA 31 (2014): 54-84

http://www.publius.us.es/estudios_andaluces 
diputaciones) que forman parte del Grupo de Trabajo de Callejero, creado en el seno de la actual Comisión Técnica de Estadística y Cartografía de Andalucía.

Otra paso más hacia la integración en la información sobre direcciones y callejero ha sido la sincronización realizada entre el CDAU y el sistema de Gestión de Entidades Territoriales de Andalucía (GESTA), el cual almacena y mantiene actualizadas, en una base de datos alfanumérica, todos las viviendas y locales de Andalucía, nutriéndose de fuentes de información como son el Callejero del Censo Electoral del INE, ficheros de intercambio con las Comunidades Autónomas de la Dirección General del Catastro, el Registro de Población de Andalucía (RPA) o el Directorio de Empresas y Establecimientos con Actividad Económica en Andalucía. Así, para cada inmueble de la Comunidad Autónoma el CDAU aportará las coordenadas a nivel de aproximación postal.

En otro ámbito regional, es de destacar el carácter pionero del Sistema de Información Territorial de Navarra (SITNA) que desde el año 2000 trabaja en la integración, actualización, gestión y difusión de la información y el conocimiento de su territorio en un entorno colaborativo. En la temática de direcciones y callejero hay que destacar dos proyectos claves: el Gestor de Direcciones Postales (GDP) aprobado por el Plan de Actuación de la Comisión de Coordinación del SITNA (2005),y EURADIN, sobre la armonización de direcciones en la implantación en el ámbito de Inspire.

Dentro de la estructura funcional del GDP se sitúa el Directorio de Direcciones Postales (DDP) cuyas propiedades más notables son su carácter integrado, pues cada titular competencial aporta su información al sistema; su grado de actualización continua; la unicidad que se pretende alcanzar dentro del marco normativo y funcional; su concepción geográfica almacenando todos los elementos en bases de datos espaciales; y la interoperabilidad que permite satisfacer las necesidades de cualquier otra actividad estadística y/o territorial.

¿Cuál es el gran reto de un sistema integrado de direcciones? No es otro que la consecución de una base de datos, en este caso espacial, que deba ser tomada como referencia y con carácter obligatorio para cualquier aplicación informática que desarrollen las administraciones públicas y en las que aparezca el componente dirección postal, siendo necesario su difusión entre la ciudadanía y en los ámbitos empresarial e investigador.

\subsection{EL MODELO DE DIRECCIONES DE LA AGE: ¿LA INTEGRACIÓN DEFINITIVA?}

Desde el GTT sobre direcciones y callejero se está avanzando hacia la consecución de un sistema integrado, surgido del consenso entre las distintas administraciones implicadas, siendo pieza fundamental la aprobación de un modelo de datos común que conforme la estructura de una base de datos espacial para permitir una eficiente

ISSN: 0212-8594 ISSN-e: 2340-2776. № DOI: http://dx.doi.org/10.12795/rea.2014.i31.03

REA 31 (2014): 54-84

http://www.publius.us.es/estudios_andaluces 
gestión de direcciones. No obstante, conviene aclarar que el planteamiento del modelo de direcciones se está realizando de forma independiente al modelo de callejero cuando en realidad ambos están íntimamente relacionados, lo que puede ocasionar inconvenientes para la aprobación definitiva del modelo de direcciones debido a que determinadas cuestiones de gran importancia se aplazan al comienzo de las discusiones para la modelización de los viarios, a pesar de estar en pleno rendimiento el modelo de datos del proyecto CartoCiudad.

Casi más importante que la aprobación de un modelo de aplicación definitivo para direcciones y callejero es establecer los mecanismos necesarios que permitan al mismo poder retroalimentarse para introducir cambios, debiendo ser lo suficientemente flexible como para adecuarse a variaciones no significativas.

Para la explicación del modelo (ver figura 7) se propone seguir un orden ascendente en la presentación de los elementos que lo componen; así, el objeto geográfico "Inmueble" se presenta como la totalidad de viviendas, locales o establecimientos existentes en el territorio que deben estar relacionados con una única aproximación postal que le aporta su geometría, siendo posible que más de un inmueble esté relacionado con una única aproximación postal ya que esta última aporta información hasta el nivel de número de policía.

Los inmuebles y las aproximaciones postales serían los elementos propios del tema de direcciones que se relacionarían, por un lado, con el viario perteneciente a la temática de redes de transportes $y$, por otro, con las unidades administrativas (municipio y provincia)y áreas de dirección (núcleo/diseminado, entidad singular y entidad colectiva). La primera relación es a nivel alfanumérico ya que todo portal debe poseer un código de vía que permita relacionarlo a la vía a la que pertenece, no siendo posible que forme parte de más de un vial. En cuanto a la relación con las unidades administrativas, no se menciona nada en la documentación pero lo más eficiente es que la relación se produjera a nivel geométrico ya que cada uno de los elementos deben estar contenidos en el de orden jerárquico superior (por ejemplo, una entidad singular solo puede pertenecer a una entidad colectiva y la misma está compuesta por la unión de una o varias entidades singulares).

\section{DIFICULTADES PARA LA GENERACIÓN DE UN SISTEMA INTEGRADO.}

\subsection{CONSIDERACIONES GENERALES.}

El principal reto al que se enfrenta la administración pública para la generación de un sistema integrado de direcciones y callejero no está en la elaboración de un modelo de datos consensuado por los distintos organismos, sino en su implementación, ya que requerirá de un marco normativo en el que se encuadren las distintas actividades administrativas y se determine qué organismos poseen competencias en la gestión del

ISSN: 0212-8594 ISSN-e: 2340-2776. № DOI: http://dx.doi.org/10.12795/rea.2014.i31.03

REA 31 (2014): 54-84

http://www.publius.us.es/estudios_andaluces 
Figura 7. Diagrama simplificado con las entidades del modelo.

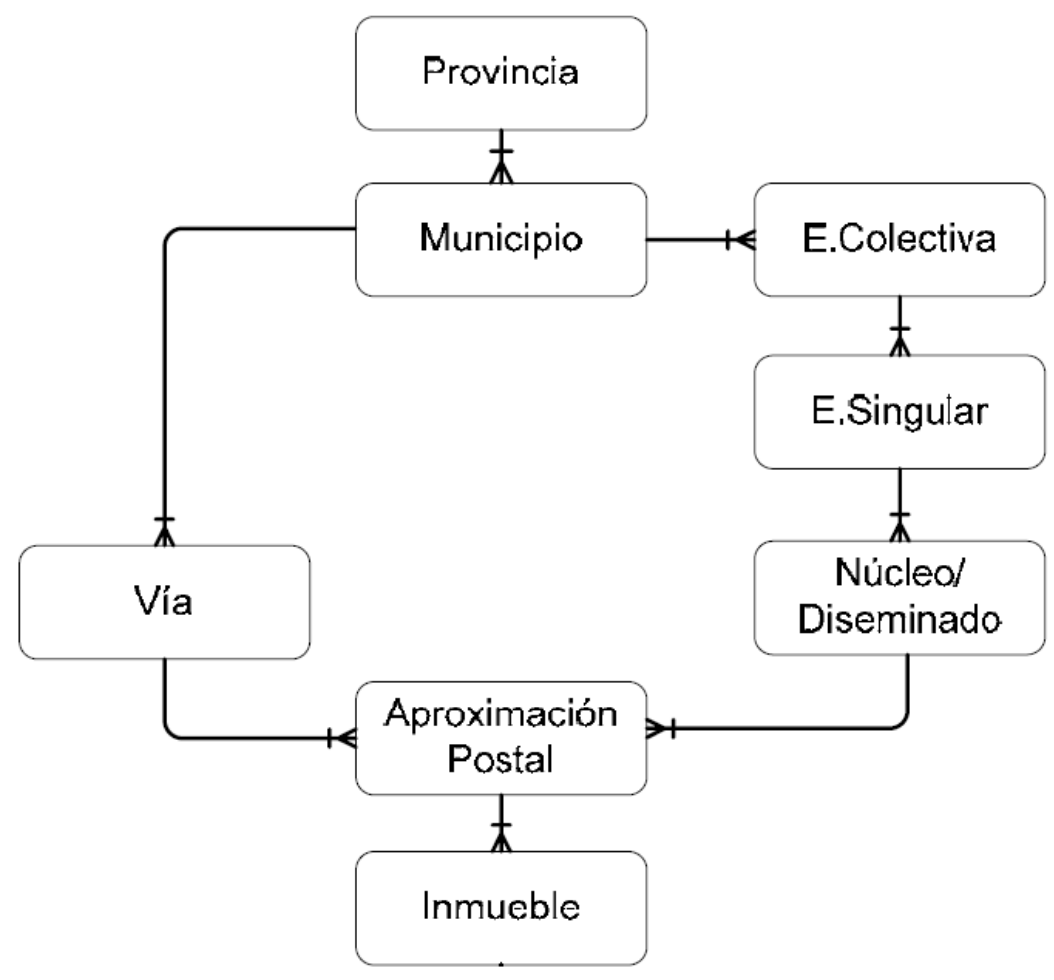

Fuente: Modelo de Direcciones de la Administración General del Estado v2 (2012).

dato; de un plan de comunicación que canalice toda la información y propuestas de mejora; de medios financieros, tecnológicos y humanos que permitan la gestión adecuada y de voluntad política para llevarlas a cabo.

En la actualidad, se considera que la gestión de información relativa a direcciones es competencia del INE y de los ayuntamientos ya que por medio de la Ley 7/1985 se establecía que los ayuntamientos eran los encargados de la gestión de los Padrones municipales y el INE asumía tareas de coordinación para evitar posibles errores y duplicidades, ampliándose los aspectos legales por medio del Real Decreto 1690/1986 relativo al reglamento de población y demarcación territorial de las entidades locales y el Real Decreto 2612/1996 que modifica el anterior.

Sin embargo, tal y como se ha señalado en el presente artículo, las direcciones con población empadronada no son las únicas existentes, ya que hay multitud de viviendas sin población registrada, establecimientos (industriales, comerciales, etc.) con o sin actividad, lugares como miradores, parques urbanos o periurbanos, restos arqueológicos, cuevas, etc., cuya dirección debe ser gestionada; por ello, se hace necesaria la publicación de una normativa específica sobre direcciones que establezca qué organismos son los competentes en su gestión.

ISSN: 0212-8594 ISSN-e: 2340-2776. № DOI: http://dx.doi.org/10.12795/rea.2014.i31.03 
Por otro lado, nos encontramos con el tema de la titularidad y de la competencia en materia de gestión viaria, tradicionalmente relacionado con los ayuntamientos que, según la normativa ya mencionada, son los encargados de gestionar y dar una denominación a los viales. No obstante, esto puede ser cierto para viales en los que reside población y, por tanto, deben ser gestionados por el Padrón de habitantes, pero no tiene fundamento legal para esa multitud de vías que permiten la movilidad por el territorio y que, por lo general, están ubicadas en zona rústica, siendo de titularidad heterogénea, en ocasiones pública y en otras privada.

Por ejemplo, tenemos el caso de las carreteras que se regulan por la Ley $25 / 1988$, de Carreteras, definiéndolas como "las vías de dominio público y uso público proyectadas y construidas fundamentalmente para la circulación de vehículos automóviles", clasificadas en autopistas, autovías, vías rápidas y carreteras convencionales. Son carreteras estatales las integradas en un itinerario de interés general o cuya función en el sistema de transporte afecte a más de una Comunidad Autónoma, conformándose la Red de Carreteras del Estado (aproximadamente 26.000 kms.) dependientes del Ministerio de Fomento; además, las distintas regiones autonómicas podrán crear legislación complementaria ${ }^{6}$.

El artículo 40.2 de la Ley 25/1988 regula el tema competencial sobre las denominadas travesías estableciendo que "las carreteras estatales o tramos determinados de ellas se entregarán a los Ayuntamientos respectivos en el momento en el que adquieran la condición de vías urbanas", adquiriendo tal condición si se cumplen las siguientes condiciones expuestas en el artículo 127.1 del Real Decreto 1812/1994 por el que se regula el Reglamento General de Carreteras: que el tráfico sea mayoritariamente urbano y que exista alternativa viaria que mantenga la continuidad de la Red de Carreteras del Estado y proporcione un mejor nivel de servicio.

En el caso de los caminos destaca la complejidad de los mismos tanto en sus tipos (carril, senda, cañada, vereda, etc.) como en su titularidad (público -gestionado por una administración pública estatal, autonómica o local- o privado). Habría que poner en relación los conceptos de titularidad, que está referido a la posesión legal de un bien, y el de adscripción del bien, que es cuando la gestión de un bien privado es traspasado a un organismo público para su vinculación directa a un uso o servicio de su competencia o para el cumplimiento de sus propios fines (Villalvilla, H., 2010). Por último, entre las vías urbanas, mayoritariamente de titularidad pública, también

\footnotetext{
${ }^{6}$ La Ley 8/2001, de 12 de julio, de Carreteras de Andalucía establece la Red de Carreteras de Andalucía constituida por aquellas que discurren íntegramente en el territorio andaluz, no están comprendidas en la Red de Carreteras del Estado y se encuentran incluidas en el Catálogo de Carreteras de Andalucía (unos 19.300 kms.) que las clasifica en dos tipologías: la red autonómica, que comprende la red básica, la red intercomarcal y la red complementaria; y la red provincial, compuesta por la red comarcal y la red local. Otros ejemplos serían el Decreto Legislativo 2/2009, de 25 de agosto, por el que se aprueba el texto refundido de la Ley de Carreteras (de Cataluña) o la Ley 7/1995, de 27 de abril, de Carreteras de Extremadura).
}

ISSN: 0212-8594 ISSN-e: 2340-2776. № DOI: http://dx.doi.org/10.12795/rea.2014.i31.03 
existen algunas que son privadas, como es el caso de urbanizaciones cerradas que internamente están estructuradas por medio de viales que dan acceso a cada una de las viviendas que la componen.

La puesta en funcionamiento de un sistema integrado de direcciones necesitará de un robusto plan de comunicación que permita canalizar toda la información necesaria, así como dar respuesta a dudas, quejas y sugerencias, entre el coordinador del sistema y las distintas administraciones implicadas, haciendo partícipe a la ciudadanía (tanto personas individuales como agentes sociales) y permitiendo un proceso de comunicación circular, es decir, que no esté limitado a la comunicación externa (hacia afuera en un único sentido). Desde el momento en que las competencias en la gestión de direcciones y viarios están repartidas entre distintas administraciones, se hace fundamental que la cooperación interadministrativa funcione correctamente ya que de ello dependerá el éxito o el fracaso de todo proyecto.

La eficiencia de este sistema es tal que, aunque requerirá de una considerable dotación de recursos, tanto financieros, tecnológicos y humanos, el valor añadido que generará supondrá un importante ahorro a corto plazo beneficiando a la sociedad en su conjunto, tanto a las Administraciones Públicas como a las empresas y profesionales que dispondrán de una información relevante para la elaboración de estudios territoriales, económicos, demográficos, ambientales, etc.

\subsection{ADECUACIÓN DEL MODELO Y CAPTURA DE INFORMACIÓN.}

El modelo de datos que se está elaborando en el seno del GTT sobre direcciones y callejero del CODIIGE debe ser el punto de partida para alcanzar el consenso entre las administraciones implicadas en la materia, si bien es necesario descender un escalón que permita pasar de los aspectos teóricos (modelo y catálogo de fenómenos) a los prácticos (captura de información), por lo que la redacción de un documento o manual de buenas prácticas en materia de direcciones y viarios sería lo recomendable.

Cuando se desciende al plano práctico y es necesario capturar un objeto geográfico para almacenarlo en la base de datos espacial, surgen muchas dudas a los que los técnicos en la materia tienen que enfrentarse y dar una solución lo más acertada posible, a pesar de no disponer de una documentación lo suficientemente esclarecedora en la que apoyarse. La experiencia diaria en la gestión de direcciones y viarios debe servir para aportar posibles mejoras que se pudieran implementar, teniendo presente que la inserción de modificaciones en el modelo no debe suponer cambios importantes $y$, por tanto, puedan ser asumidas por las aplicaciones específicas creadas a partir del modelo de datos común. Por el contrario, si las mejoras a introducir cambian sustancialmente el modelo, habría que analizar las ventajas e inconvenientes de su implementación y rechazarlas en caso de ser más perjudiciales que beneficiosas.

ISSN: 0212-8594 ISSN-e: 2340-2776. № DOI: http://dx.doi.org/10.12795/rea.2014.i31.03 
¿Se deben recoger todos los viales existentes en el territorio?

En principio, no hay ninguna limitación procedente de Inspire, LISIGE o de las especificaciones de CartoCiudad, por lo que se recogerían todos los viales que se pudieran detectar. No obstante, conviene aclarar que las administraciones públicas solo poseen competencias sobre el viario de uso público, por lo que para los de titularidad y uso privado no tendrían respaldo jurídico para su gestión; por tanto, en caso de formar parte de la red viaria y servir de apoyo para actividades del sector público como la gestión de emergencias (necesitan disponer de todos los viales existentes para acceder a localizaciones que requieran de su intervención), sería necesario determinar qué organismo debe asumir las competencias en la digitalización y actualización de las de carácter privado.

En ocasiones, los ayuntamientos discrepan en relación a la inclusión en la red viaria de aquellos viales de uso privado o que por sí mismos no permiten acceder a una dirección y que, por lo general, no disponen de una denominación específica, sobre todo teniendo en cuenta que a la hora de generar un servicio web de mapas, la presentación de estos elementos no resulta vistosa, no obstante, no es difícil aplicar filtros sobre los datos mediante el uso de aplicaciones "web mapping" (GeoServer, MapServer, etc.) que permiten ajustar la visualización a todo tipo de requerimientos.

Denominación de los viales.

El Grupo de Expertos de las Naciones Unidas en Nombres Geográficos (UNGEGN) define nombre geográfico (o nombre propio topográfico o topónimo) como nombre propio dado a un accidente sobre la superficie de la Tierra, ya sean lugares poblados (ciudades, pueblos, aldeas), divisiones administrativas (estados, regiones, municipios), accidentes geográficos naturales (lagos, ríos, valles, montañas) o artificiales (presas, puertos, viarios), o zonas no delimitadas pero reconocidas a nivel local (parajes, huertas, pastizales). Es muy frecuente que un mismo nombre geográfico tenga distintos alónimos (cada uno de los nombres diferentes que designan un mismo elemento geográfico) ya sea por la distinción entre lenguas o debido a variantes, por lo que se hace necesario determinar un nombre preferente que, en caso de ser de carácter oficial, estaríamos hablando de la normalización del mismo.

Entre las ventajas de la adopción de un programa de normalización de nombres geográficos está la de garantizar la eficiencia de la administración y de las comunicaciones en una sociedad como la actual, en la que las TICs han asumido un papel preponderante en las relaciones sociales y es necesario que permitan economizar tiempo y recursos económicos en campos tales como la cartografía; las comunicaciones terrestres, marítimas y aéreas; los estudios demográficos y

ISSN: 0212-8594 ISSN-e: 2340-2776. № DOI: http://dx.doi.org/10.12795/rea.2014.i31.03 
territoriales; la distribución de mercancías; la planificación de los servicios sociales y asistenciales, etc.

Siguiendo las principales recomendaciones de la Norma Técnica sobre Normalización Toponímica del Sistema Estadístico y Cartográfico de Andalucía (NTCA 02-021), acorde con las propuestas del UNGEGN y el CENG (Comisión Especializada de Nombres Geográficos), y teniendo en cuenta que están bastante orientadas a la representación (ya sea en formato papel o digital) del topónimo, se deberían respetar una serie de consideraciones: debe recogerse el topónimo completo (término genérico y específico) en los nombres de edificaciones rurales y odónimos (nombre que designa una vía terrestre de comunicación);el tratamiento sistemático de los nombres no debe ser motivo para la supresión de elementos significativos que afecten al término específico del topónimo; deberán acentuarse de acuerdo con las reglas ortográficas, incluidas las mayúsculas; no deben realizarse abreviaturas; debe permitirse la aglutinación del topónimo (fenómeno frecuente, sobre todo en el lenguaje oral que tiende a acortar las palabras); los números cardinales u ordinales y las fechas, excepto los años, se escribirán con letras, a menos que algún organismo haya normalizado el topónimo con cifras; no deben utilizarse paréntesis con información aclaratoria sobre el topónimo que, en cualquier caso no forma parte del mismo, etc.

Al analizar el tipo de fenómeno "Via" del modelo de aplicación de direcciones de la AGEse observa que existen dos atributos que tienen relación con la denominación de los viales, "tipoVia" (según la tipología oficial recogida por los ayuntamientos y almacenado por el INE) que se asimilaría con el término genérico de un topónimo y que lo identifica de forma general (por ejemplo, avenida, calle, camino, plaza); y "dVia" (nombre oficial de la vía procedente del ayuntamiento correspondiente y que recoge el INE) que sería el topónimo específico y lo identifica de manera particular. Se podría añadir un nuevo campo intermedio entre los anteriores (Inspire la incluye como opcional en atención a una recomendación de la Universal Postal Union) para recoger los artículos existentes (NamePrefix) entre el tipo de vía y su denominación.

Aparte de considerar que existen otros organismos que también tienen potestad para determinar el nombre oficial de un vial, convendría incluir un campo que estuviera referido al nombre geográfico completo (término genérico y término específico) y que, además, sirviera para el etiquetado en servicios de mapas u otras aplicaciones. Ahora bien, la información que aporta el INE en cuanto a la denominación de los viales resulta alejada de los requerimientos de la normalización de nombres geográficos (no se distingue entre mayúsculas y minúsculas; no se aplican las normas de acentuación; los artículos iniciales del término específico pasan al final de la denominación y se encierran entre paréntesis; en ocasiones se genera al final del nombre específico un paréntesis con información de la entidad singular, núcleo de población o cualquier otro

ISSN: 0212-8594 ISSN-e: 2340-2776. № DOI: http://dx.doi.org/10.12795/rea.2014.i31.03 
literal que se considere identificativo), por lo que se hace necesario una adaptación del diseño de registro ${ }^{7}$.

En cuanto a viales que se sitúan en la línea límite municipal de dos municipios y que en cada uno de ellos posee una denominación se debería recurrir a la cooperación interadministrativa y a la coordinación efectiva del INE en materia de denominaciones de vías, para evitar que una misma vía física esté nombrada de manera diferente en cada uno de los municipios. Además, será necesaria la coordinación a nivel geométrico.

Tipologías de vías que no se asocian a objetos geográficos lineales.

Actualmente, en la tipología de viales del INE, se incluyen tipos que hacen referencia a localizaciones que no se ajustan al concepto de vial como objeto geográfico de tipo lineal, siendo puntuales (alquería ${ }^{8}$, apartamentos, bloque, caserío ${ }^{9}$, cobertizo, cortijo) que serían considerados como edificios por lo que deben ser numerados y formar parte de las aproximaciones postales; zonales referidos al poblamiento (aldea, alquería, arrabal, barriada, barrio, caserío, colonia, complejo, conjunto, grupo, lugar, poblado, urbanización)que conformarían la amalgama de entidades del denominado por Inspire como "AddressAreaName" que, sin ser una unidad administrativa, sí posee un nombre propio e identificable; topónimos zonales referidos a accidentes geográficos naturales (cerro, costa, falda, hoya, ladera, lago, monte, pago, paraje, pinar, playa, valle, vega) que deberían formar parte de los nomenclátores geográficos; y otros tipos zonales (demarcación, explanada, extramuros, extrarradio, finca, jardín, parque, polígono, rincón, sector, zona) más indeterminados, aunque la mayor parte relacionados con el urbanismo. Por tanto, es necesario realizar un esfuerzo para determinar cuáles serán los tipos de vía oficiales, teniendo en cuenta que deberán adecuarse a abstracciones de la realidad de tipo lineal.

\section{Geometría de portales y viales.}

La abstracción de la realidad territorial para el almacenamiento de los objetos geográficos en una base de datos espacial es compleja, presentando multitud de elementos que no se ajustan con el modelo teórico idóneo, lo que genera la necesidad de presentar los distintos casos de uso en un documento que sirva de referencia para la captura de información. De esta forma, las especificaciones de CartoCiudad pueden

\footnotetext{
${ }^{7}$ El diseño de registro se establece por medio de la Orden de 11 de Julio de 1997 sobre comunicaciones electrónicas entre las Administraciones públicas referentes a la información de los Padrones municipales.

${ }^{8}$ EI DRAE ofrece dos acepciones: la primera la relaciona con una casa de labor con finca agrícola, típica del Levante peninsular (objeto puntual), y la segunda, la asimila a un conjunto formado por un número reducido de casas (objeto zonal referido al poblamiento).

${ }^{9}$ Puede considerarse tanto objeto puntual (casa de labor típica del País Vasco y Navarra) como objeto zonal referido al poblamiento (conjunto formado por un número reducido de casas).
}

ISSN: 0212-8594 ISSN-e: 2340-2776. № DOI: http://dx.doi.org/10.12795/rea.2014.i31.03

REA 31 (2014): 54-84

http://www.publius.us.es/estudios_andaluces 
tomarse como referencia para la correcta digitalización de los tramos viales existentes ofreciendo, entre otras, las siguientes pautas generales:

- Se digitalizarán los ejes de todas las calzadas, incluyendo las peatonales y los carriles bici, de forma que la simulación de una ruta por los tramos que compongan los ejes refleje de forma fidedigna la trayectoria que describiría un vehículo o un peatón al seguirla.

- No se digitalizarán tramos correspondientes a caminos dentro de parques o carriles dentro de un aparcamiento.

- Se dibujará un solo eje para cada vía en aquellas en las que no exista separación física entre los carriles que tienen diferente sentido y en las que hay evidencias de que la circulación se realiza en un sólo sentido.

- Se dibujarán dos ejes para cada vía en los casos en los que exista algún tipo de separación física: vallas de protección, bulevares, medianas, refugios para peatones en mitad de la calzada, marcas de pintura, diferentes a las líneas de separación de carriles de diferente sentido, etc. Se conectarán ambos ejes mediante un tramo en el caso de observarse interrupción de la mediana o paso de cebra que comunique los dos carriles, para hacer más real el cálculo de rutas.

- Los ejes de cada vía se dividirán en tramos siempre y cuando se cambie de vial, haya una intersección real al mismo nivel con otra vía o ficticia con los límites administrativos, o cambie el valor de cualquiera de los atributos de la vía representada por el tramo.

Sin embargo, cuando el técnico se dispone a digitalizar un tramo de vial se le presentan una serie de problemas para el correcto mapeado del objeto geográfico, como pueden ser ciertos viales peatonales, puesto que la movilidad no está tan restringida como para los vehículos, el dibujo de las plazas rodeadas por calles, o la determinación de los puntos de unión (para la creación de nodos) en cruces de varios viales.

En general, un portal debe estar situado en el borde de la parcela o del edificio al que pertenezca, en función de la precisión que se pretenda alcanzar; así, se podrán relacionar con la cartografía catastral y poder tener asignado de forma automática (mediante geoprocesos) la referencia catastral, información relevante para la realización de estudios relativos a la propiedad, la gestión tributaria, etc.

\section{Viales que atraviesan más de un municipio.}

Existen multitud de casos (carreteras, caminos, etc.) en los que un vial discurre por más de un municipio y que según el modelo de datos cada uno de esos tramos debe conformar una vía distinta que, aunque posea el mismo nombre, su código debe ser diferenciado. En este sentido, conviene reflejar mi contrariedad ante esta forma de modelar que está influenciada por la normativa en materia de población que tiene

ISSN: 0212-8594 ISSN-e: 2340-2776. № DOI: http://dx.doi.org/10.12795/rea.2014.i31.03 
puestas sus miras en la gestión padronal a nivel municipal y no tiene en cuenta que existen viales cuya competencia no es la municipal y su realidad territorial va más allá que la entidad municipio.

Relación de los viales con el fenómeno "NucleoDiseminado".

En las instrucciones técnicas de la Resolución de 1 de abril de 1997 referidas a la gestión y revisión del Padrón municipal se establece que dentro de un municipio los nombres de los viales (tipo y denominación) no podrán repetirse, aunque incluye la excepción para vías que pertenezcan a núcleos de población diferentes, por lo que se insta a los ayuntamientos a deshacer las ambigüedades mediante la inclusión de un paréntesis al final de la denominación en el que se recoja el nombre de la entidad singular, el núcleo de población o cualquier otro literal que lo identifique, así como la asignación de un código de vía diferente.

Desde el IGN, dentro del GTT sobre direcciones y callejeros, se han planteado diversas soluciones a esta problemática mediante la utilización de una tabla intermedia que ponga en relación a los viales con los núcleos de población en los que se insertan, no obstante, parece más lógico que para una gestión eficiente de los viales se inste a los ayuntamientos a la modificación de la denominación de las vías que estén repetidas y así poder simplificar el modelo de datos, aunque hay que tener en cuenta que los ayuntamientos no consideran de buen recibo modificar el nombre oficial del mismo.

\section{¿Aclaración entre los objetos geográficos de aproximación postal e inmueble?}

En el modelo de direcciones de la AGE se definía el inmueble como la totalidad de viviendas, locales o establecimientos existentes en el territorio, estando relacionado con una única aproximación postal, la cual le aporta su geometría al nivel de dirección horizontal (por tanto, el inmueble no posee geometría). Un edificio o construcción puede estar compuesto de un único inmueble o de la agrupación de varios, por tanto, el punto más exacto definido para una aproximación postal sería la puerta de entrada o acceso al edificio o al recinto del mismo. Así, un local comercial siempre será un inmueble aunque su puerta de acceso coincida con la de entrada al edificio. Podríamos terminar diciendo que una aproximación postal es el objeto geográfico que le aporta la geometría a un inmueble.

Esta aclaración viene dada por la inclusión por parte de algunos ayuntamientos en la información de portales o números de policía de los locales comerciales que, a mi parecer, no es correcta, ya que como portal (o aproximación postal) solo deben figurar los edificios que, en caso de poseer una única vivienda o local coincidiría la puerta de acceso pero, para el caso de edificios formados por varios locales comerciales, aunque su acceso se realice directamente desde un vial, no por ello deja de ser un inmueble del edificio con la misma aproximación postal que el resto. De la misma forma, los

ISSN: 0212-8594 ISSN-e: 2340-2776. № DOI: http://dx.doi.org/10.12795/rea.2014.i31.03

REA 31 (2014): 54-84

http://www.publius.us.es/estudios_andaluces 
garajes o cocheras no pueden considerarse aproximaciones postales puesto que se trata de locales destinados a guardar automóviles y, como tales, están incluidos en la definición de inmueble.

La Resolución de 9 de abril de 1997 genera confusión en este sentido ya que en el apartado a) referido a la numeración de edificios aclara que "deben numerarse todas las entradas principales e independientes que den acceso a una vivienda o local, dejando sin numerar las entradas accesorias o bajos como tiendas, garajes, dependencias agrícolas, bodegas, y otras, las cuales se entiende que tienen el mismo número que la entrada principal que les corresponde". No obstante, menciona que existen excepciones cuando en una vía urbana existen laterales o traseras de edificios, con presencia de tiendas o garajes, ya numerados en otras vías, y cuyo único acceso sea por dicho lateral o trasera.

Por último, nos encontramos con edificios que poseen más de una entrada al mismo además de la principal, por lo que estos accesos pueden considerarse como una aproximación postal, siendo necesario distinguirlas, por ello, el modelo de datos de direcciones de la AGE incluye el campo "entradaPpal".

\section{Direcciones en diseminado.}

La complejidad para la determinación de las direcciones en diseminado tiene su origen en la gestión alfanumérica de las mismas lo que ha ocasionado a menudo gran confusión para conocer con certeza la ubicación de una dirección. De esta forma, el Real Decreto 2612/1996 añade el deber de los ayuntamientos de mantener la cartografía sobre direcciones postales o, en su defecto, de referenciarla de manera precisa con la cartografía elaborada por la Administración competente, poniendo de manifiesto que es la manera más eficiente para su gestión. Además, la Resolución de 9 de abril de 1997 en el apartado d) referido a la numeración de los edificios confirma que los edificios situados en diseminado también deberán estar numerados, dando dos opciones: por un lado, si están distribuidos a lo largo de caminos, carreteras u otras vías, sería aconsejable que se numeraran de la misma forma que las vías urbanas y, por otro, si la dispersión de los mismos fuera destacable, se mantendrá una numeración correlativa dentro de la entidad de población a la que pertenezca. Atendiendo a esta disposición, podríamos dudar de la necesidad de mantener como una aproximación postal a los puntos kilométricos de las carreteras ya que si se mantiene este hecho también se deberían registrar los puntos kilométricos de los caminos u otros viales no urbanos. No obstante, aun sin estar conforme con su integración en el fenómeno de aproximación postal, podría mantenerse de forma transitoria mientras que no se ofreciera una solución satisfactoria a las direcciones relacionadas con puntos kilométricos.

ISSN: 0212-8594 ISSN-e: 2340-2776. № DOI: http://dx.doi.org/10.12795/rea.2014.i31.03 
Relación de los portales con las entidades zonales.

Un aspecto de gran interés para diversos estudios es la relación existente entre una aproximación postal y la unidad poblacional, el código postal o la sección censal a la que pertenece. El mantenimiento de estas relaciones no se debe ejecutar por medio de la introducción alfanumérica y manual de la información sino mediante la utilización de herramientas SIG (geoprocesos) a partir de capas elaboradas para cada una de las temáticas, siendo muy importante que las mismas estén actualizadas para evitar errores de asignación.

\section{CONCLUSIONES.}

El estudio realizado en el marco del proyecto EURADIN ha cuantificado en 60.000 millones de euros anuales el valor añadido derivado de la disponibilidad de un sistema integrado de direcciones en Europa (Valentín, A., 2011), lo que ha derivado en un mayor interés por parte de las administraciones por alcanzar la integración y la completa georreferenciación de las mismas, máxime teniendo en cuenta la grave crisis económica actual y la existencia de una creciente demanda social, principalmente desde sectores económicos como el comercio electrónico, el geomarketing y análisis de mercados, o los servicios de paquetería y distribución de mercancías.

Para que funcione correctamente un sistema integrado de direcciones, más allá de un marco jurídico que establezca las competencias, funciones, mecanismos y medios tecnológicos y humanos que cada administración u organismo deba gestionar, es necesario que la implementación del mismo se ejecute mediante un "Gestor de Direcciones Postales", por medio del cual cada registro administrativo que aporte información sobre una dirección deberá hacer uso de alguna de las ya almacenadas en el sistema, debiendo ser asignada mediante búsquedas informatizadas y, en el caso de no existir una adecuada, se deberá generar una incidencia para su inclusión en el Gestor.

Además, la integración de las direcciones postales va a permitir la georreferenciación de toda la población y de las actividades económicas lo que contribuirá a mejorar la planificación y gestión territorial, socioeconómica o medioambiental.

\section{BIBLIOGRAFÍA.}

Anguix, A. (2005): "gvSIG: creación de un SIG Open Source", en 4̣a Semana Geomática.

Arnaud, A.M.; Silva, H.; Geirinhas, J. and Julião, R.P. (2010): “O Projecto EURADIN como suporte à constituição da Infra-Estrutura Nacional de Geo-referenciação Indirecta, em

ISSN: 0212-8594 ISSN-e: 2340-2776. № DOI: http://dx.doi.org/10.12795/rea.2014.i31.03

REA 31 (2014): 54-84

http://www.publius.us.es/estudios_andaluces 
conformidade com a directiva INSPIRE", en I Jornadas Ibéricas de Infraestructuras de Datos Espaciales.

Comisión Interdepartamental de Estadística y Cartografía de Andalucía (2013): NTCA 02-021. Norma Técnica Cartográfica sobre Normalización Toponímica.

Directiva 2007/2/CE del Parlamento Europeo y del Consejo de 14 de marzo de 2007 por la que se establece una infraestructura de información espacial en la Comunidad Europea (Inspire).

Francés, J. and Velasco, A. (2010): "CartoCiudad", en 'Territorial 2010',Conferencia sobre Sistemas de Información Territorial.

García, A.; González, J; González, A.; Mas, S.; Rubio, J.M.; Velasco, A. and Verdejo, P. (2011): "Propuesta de modelo de callejero: un primer paso en la interoperabilidad de los Modelos de Direcciones y de Transportes", en II Jornadas Ibéricas de Infraestructuras de Datos Espaciales.

García, A.; González, A.; González, J. and Mas, S. (2010): “Evolución del Proyecto CartoCiudad en 2010", en I Jornadas Ibéricas de Infraestructuras de Datos Espaciales.

González, A. (2011):"INSPIRE. Norma de ejecución de direcciones", en Reunión del Grupo de Trabajo de la Infraestructura de Datos Espaciales de España.

González, A.; GONZÁLEZ GARCÍA, J.; Mas, S.; Rubio, J.M. and Velasco, A. (2011): Catálogo de Fenómenos CartoCiudad v 10.0. Instituto Geográfico Nacional.

González. A.; González, J.; Mas, S.; Rubio, J.M. and Velasco, A. (2013): Especificaciones del producto CartoCiudad v 10.1. Instituto Geográfico Nacional.

Grupo Técnico de Trabajo sobre Direcciones y Callejero (2012): Modelo de Direcciones de la Administración General del Estado v2. Consejo Directivo de la Infraestructura de Información Geográfica de España.

Inspire, Thematic Working Group Addresses (2014): D2.8.I.5 Data Specification on Addresses -Technical Guidelines.

Inspire, Thematic Working Group Addresses (2014): D2.8.I.3 Data Specification on Geographical Names -Technical Guidelines.

Inspire, Thematic Working Group Addresses (2014): D2.8.I.5 Data Specification on Transport Networks -Technical Guidelines.

Inspire, Thematic Working Group Addresses (2014): D2.8.I.5 Data Specification on Administrative Units -Technical Guidelines.

ISSN: 0212-8594 ISSN-e: 2340-2776. № DOI: http://dx.doi.org/10.12795/rea.2014.i31.03 
Ley 7/1985, de 2 de abril, Reguladora de las Bases del Régimen Local.

Ley 25/1988, de 29 de Julio, de Carreteras.

Ley 4/2010, de 5 de julio, sobre las infraestructuras y los servicios de información geográfica en España.

Ministerio de Fomento (1998): Vías de dependencia municipal. Subdirección General de Estadística y Estudios.

Moreno, A. (2011): "La base de referencia para la geocodificación: el Callejero Digital de Andalucía", en Mapping, no 148, págs. 40-43.

Naciones Unidas (2007): Manual para la normalización nacional de los nombres geográficos. Grupo de Expertos de la Naciones Unidas en Nombres Geográficos. Departamento de Asuntos Económicos y Sociales.

Orden de 23 de julio de 2001 por la que se regula la entrega a los Ayuntamientos de tramos urbanos de la Red de Carreteras del Estado.

Real Decreto 1690/1986, de 11 de julio, por el que se aprueba el Reglamento de Población y Demarcación Territorial de las Entidades Locales.

Real Decreto 2612/1996, 20 diciembre, por el que se modifica el Reglamento de Población y Demarcación Territorial de las Entidades Locales aprobado por el Real Decreto 1690/1986, de 11 de julio.

Real Decreto Legislativo 1/2004, de 5 de marzo, por el que se aprueba el texto refundido de la Ley del Catastro Inmobiliario.

Resolución de 9 de abril de 1997, de la Subsecretaría, por la que se dispone la publicación de la Resolución de 1 de abril de la Presidenta del Instituto Nacional de Estadística y del Director general de Cooperación Territorial, por la que se dictan instrucciones técnicas a los Ayuntamientos sobre la gestión y revisión del padrón municipal.

Ríos, J. (2010): "Modelo para el mantenimiento del callejero y portalero a través de Diputaciones, Ayuntamientos, etc.", en XVII Jornadas de estadística de las Comunidades Autónomas.

Valentín, A. (2011): "Por un sistema integrado de direcciones postales", en Mapping, no 149, págs. 63-67.

ISSN: 0212-8594 ISSN-e: 2340-2776. № DOI: http://dx.doi.org/10.12795/rea.2014.i31.03 
Valentín, A. (2012): “Información geográfica y estadística en las Comunidades Autónomas", en Revista de Información estadística y Cartográfica de Andalucía, no 2, págs. 49-55.

Villalvilla, H. (2010): "Los caminos y servidumbres públicas y sus titulares. Como desentrañar un galimatías de cierta complejidad", en Revista El Ecologista, no 66. 